\title{
Compounds, phrases and clitics in connected speech
}

\author{
Hilary Wynne $^{\mathrm{a}, *}$, Linda Wheeldon ${ }^{\mathrm{b}}$, Aditi Lahiri ${ }^{\mathrm{a}}$ \\ ${ }^{a}$ Faculty of Linguistics, Philology \& Phonetics, University of Oxford, Walton Street, Oxford OX1 2HG, UK \\ ${ }^{\mathrm{b}}$ University of Agder, Norway
}

\section{A R T I C L E IN F O}

\section{Article history:}

Received 8 June 2016

Received in revised form 27 July 2017

Available online $\mathrm{xxx}$

Keywords:

Language production

Prosodic structure

Phonological encoding

Compounds and adjective-noun phrases

Compounds and clitics

\begin{abstract}
A B S T R A C T
Four language production experiments examine how English speakers plan compound words during phonological encoding. The experiments tested production latencies in both delayed and online tasks for English noun-noun compounds (e.g., daytime), adjective-noun phrases (e.g., dark time), and monomorphemic words (e.g., denim). In delayed production, speech onset latencies reflect the total number of prosodic units in the target sentence. In online production, speech latencies reflect the size of the first prosodic unit. Compounds are metrically similar to adjective-noun phrases as they contain two lexical and two prosodic words. However, in Experiments 1 and 2, native English speakers treated the compounds as single prosodic units, indistinguishable from simple words, with RT data statistically different than that of the adjective-noun phrases. Experiments 3 and 4 demonstrate that compounds are also treated as single prosodic units in utterances containing clitics (e.g., dishcloths are clean) as they incorporate the verb into a single phonological word (i.e. dishcloths-are). Taken together, these results suggest that English compounds are planned as single recursive prosodic units. Our data require an adaptation of the classic model of phonological encoding to incorporate a distinction between lexical and postlexical prosodic processes, such that lexical boundaries have consequences for post-lexical phonological encoding.
\end{abstract}

\section{Introduction}

\section{Psychological processes involved with speaking}

Language production models agree that there are a series of cognitive stages involved in the production of speech. Each of these stages prepares corresponding representations, e.g. concepts at the semantic level, lemmas and syntactic structure during grammatical encoding, and phonological representations during phonological encoding (see Griffin \& Ferreira, 2006 for a review). Numerous psycholinguistic studies have shown that the phonological encoding stage is responsible for infusing abstract lexical representations with phonological properties such as segmental ordering (e.g., Meyer, 1990, 1991; Wheeldon \& Levelt, 1995; Wheeldon \& Morgan, 2002), syllabification (e.g., Ferrand, Segui, \& Grainger, 1996; Ferrand, Segui, \& Humphreys, 1997; Morgan \& Wheeldon, 2003; Schiller, Costa, \& Colomé, 2002), and prosodification (e.g., Cholin, Schiller, \& Levelt, 2004; Damian \& Dumay, 2007; Ferreira, 1993; Jescheniak, Schriefers, \& Hantsch, 2003; Roelofs \& Meyer, 1998; Wheeldon \& Lahiri, 1997, 2002).

In early models of language production (Dell, 1986; Harley, 1984) the output of the phonological encoding stage was typically treated as a lexical word. In order to prepare an utterance for articulation, the phonological encoding stage accessed the output of the lexicalization stage (lexical words) and systematically built metrical frames accord-

\footnotetext{
* Corresponding author.

Email addresses: hilary.s.wynne@icloud.com (H. Wynne); linda.r.wheeldon@uia. no (L. Wheeldon); aditi.lahiri@ling-phil.ox.ac.uk (A. Lahiri)
}

ing to the specific phonological rules of the language. A lexical word is a well-formed semantic and syntactic unit that can stand on its own, be uttered in isolation, and even be considered a full utterance. For example, the lexical word coffee, if uttered with a question intonation, can be construed as someone asking the listener if they would like coffee. Lexical words can be morphologically complex; e.g. use, uses, disuse, using, user are all lexical words each with well-defined semantic and syntactic properties. But we know that speakers do not produce connected speech in isolated units.

Multiword utterances regularly exhibit word boundaries that are not necessarily sacrosanct, as illustrated by the famous English slogan Drinka pinta milka day. The linguistic units in this structure correspond not to the syntactic representation of the utterance (Drink a pint of milk a day) but to how it sounds in regular, connected speech, i.e. its prosodic structure. The mismatch in prosodic and lexical structure points to a process in phonological encoding where features of connected speech must be prepared: that is, where drink a becomes drinka. Accordingly, more recent psycholinguistic models of phonological encoding (Levelt, Roelofs, \& Meyer, 1999; Roelofs, 1997) no longer treat the output of the phonological encoding process as a lexical unit, but as a prosodic one.

In this paper, our focus is on the prosodic structure of two types of multiword utterances in native English speakers: compounds and phrases. We investigate two main hypotheses related to the preparation of prosodic units in English: one regarding the similarities or differences in prosodic structure of compounds and phrases, and one related to the behaviour of clitics with these items in connected speech. The first hypothesis is concerned with the prosodic structure of multi-word structures in English. Although multi-word sequences may look 
similar on the surface, they can be quite different depending on their prosodic structure. Linguistic theories of phonological phrasing maintain that prosodic units are not necessarily isomorphic with syntactic units (Lahiri \& Plank, 2010; Selkirk, 1980, 1986). These theories approach the issue of asymmetry by introducing a series of hierarchically-structured prosodic units such as phonological words and phrases.

Here, compounds prove to be rather remarkable. Both the compound White House (the residence of the American president) and the phrase white house (a house painted white) contain the same number of lexical units and the same number of prosodic units; however, when spoken in regular speech they differ in stress placement suggesting that compounds and phrases differ in structure at the prosodic level (where phonological features such as stress and intonation are assigned). Our questions are thus: are compounds and phrases processed differently during the phonological planning stage in English, and if so- to what extent does this processing reflect the difference in structure? If compounds and phrases are treated differently during the phonological planning stage, then this difference should be reflected in the time it takes the speaker to plan the utterance in which they are contained.

Our second hypothesis hinges upon the first. If English compounds and phrases are indeed treated as different prosodic structures by speakers, then this should also be observable in the behaviour of phonological clitics with these structures. Prosodic structure theory maintains that phonological clitics, such as function words such as $a$ in drink $a$ in the English slogan above, reduce and attach to prosodic units: this process is known as cliticisation. If the structural differences in compounds and phrases are predicted by the surface metrical stress, then such differences would also be predicted due to cliticisation.

In what follows, we first turn to the literature regarding the unit of planning during phonological encoding involving single lexical words. We then move to a discussion of the psycholinguistic evidence regarding multi-word units such as compounds, and phrases. Then we will focus on our two hypotheses as related to the current approaches.

\section{The unit of planning: lexical words and clitics}

When a speaker is planning a sequence of two words, they plan the conceptual, syntactic and phonological structure of the utterance. Evidence has accumulated from both linguistic and psycholinguistic research that prosodic rather than lexical structure governs phonological encoding processes in language production (Hannahs, 1995; Wheeldon \& Lahiri, 1997, 2002; Vigario, 2003). Following Levelt et al. (1999), we maintain that prosodic units known as "phonological words" are built during phonological encoding. Minimally composed of at least one stressed foot, a phonological word can contain a lexical word plus any number of unstressed items, which are most often function words such as auxiliaries (is, are, etc.), determiners (a, the, etc.), pronouns (it, he, etc.) and prepositions (to, in, etc.). Following this, the number of lexical words is often different than the number of phonological words in a multi-word utterance:

\footnotetext{
(1) Examples of lexical and phonological $(\omega)$ word formation ${ }^{\mathrm{a}}$

(a) lexical units: $[\mathrm{Tim}]_{\mathrm{N}}[\text { is }]_{\mathrm{V}}[\text { sick }]_{\mathrm{Adj}}$

prosodic units: $(\text { Timz })_{\omega}$ (sick)

(b) lexical units: $[\text { Drink }]_{\mathrm{V}}[\text { the }]_{\text {art }}[\text { juice }]_{\mathrm{N}}$

prosodic units: $(\text { drınkðə) })_{\omega}$ (juice $)_{\omega}$

$\overline{{ }^{a}}$ We use the $\omega$ symbol to notate prosodic unit (phonological word) boundaries and $\varphi$
}

for phrase boundaries consistently throughout this work.

In the examples above (1a and $1 \mathrm{~b}$ ), we can observe how unstressed items can attach to lexical words in normal connected speech, forming a single phonological word. While the sentence Tim is sick (1a) is made up of three lexical words, it is only two phonological words when spoken in regular, connected speech; through reduction, Tim is becomes [trmz]. Similarly, in drink the juice, the unstressed unit the reduces and attaches to drink, forming a single phonological word: [drinkðə]. These unstressed items are known as "phonological clitics" and the process that forms them is known as cliticisation. Further examples of this behaviour can be seen below, which reproduces the English slogan (repeated here with appropriate syntactic and prosodic bracketing):

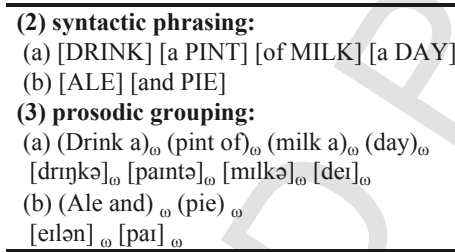

As mentioned above, cliticisation often involves function words such as auxiliaries, prepositions, pronouns, conjunctions, and articles. Examples of encliticisation, where weak forms undergo phonological change (e.g. colloquial German denn $>$ 'n), have regularly stood as evidence for default phonological phrasing which often violates the morphosyntactic structure of the utterance (cf. Saran, 1907; Sweet, 1886; Zwicky \& Pullum, 1983). Note that the boundaries of the prosodic units (example 3 ) are different than those of the morphosyntactic units (example 2) and the function words of, $a$, and encliticise to the preceding word. Thus, pint of in the example above is encoded as [pain.tz], a single prosodic unit in which the lexical and syllable boundaries do not coincide (cf. Lahiri \& Plank, 2010; Nespor \& Vogel, 1986; Peperkamp, 1997; Selkirk, 1980, 1996).

Further supportive evidence for this process comes from psycholinguistic tasks employing the prepared speech paradigm, (Sternberg, Monsell, Knoll, \& Wright, 1978; Wheeldon \& Lahiri, 1997, 2002). In a series of experiments using a delayed priming task, Wheeldon and Lahiri (1997) elicited reaction time data for utterances containing clitics in Dutch. In a series of prepared speech tasks, speakers were asked to respond to questions such as Wat zoek je? ("What do you seek?"). The authors found that the onset latencies for sentences containing clitics (e.g. Ik zoek het water, "I drink the water") were no different than those that contained none (e.g. Ik zoek water, "I seek water"). This indicated that clitics were attaching to the neighbouring word and forming a single prosodic unit, and that the number of prosodic words in both clitic and non-clitic sentences were the same. In contrast, sentences containing stressed elements that cannot encliticise (e.g. Ik zoek vers water, "I seek fresh water") had significantly longer onset latencies. This pattern held even if the first word was a full prosodic word (e.g. Riet zoekt het water, "Riet seeks the water" vs. Riet zoekt water "Riet seeks water"). The effect was also not attributable to the number of content words produced, as phrase final function words, which receive stress (e.g. Ik zoek het, "I seek $i t^{6 ")}$, did not significantly differ in onset latency from the same phrases with a final content word (e.g. Ik zoek water, "I seek water").

Direction of cliticisation was confirmed by means of an online production task on the assumption that the size of the first prosodic 
unit would predict preparation time. Thus, in Ik drink het water, if het was in fact encliticising leftwards (drinkhet), then the sentence containing the clitic would yield the longest latencies as the speaker would have to wait for the entire prosodic unit (ikdrinkhet) to be encoded before speaking. If, on the other hand, het encliticised rightwards, the preparation times would be similar to those for the non-clitic condition (ik drink water) since the speaker would only be encoding [ikdrink] as the first prosodic unit. As predicted, clitic sentences took significantly longer to produce in this task, confirming that the Dutch determiner het ("the") encliticised with the neighbouring word and formed a single prosodic word, resulting in longer onset latencies than for sentences that contained no determiner.

In summary, Wheeldon and Lahiri (1997) found that neither the number of lexical words, content words, nor syllables in an utterance predicted onset latencies in clitic sentences in Dutch. Clitics attached leftwards to the initial phonological unit [Ik zoek], forming a single phonological word [Ik zoek het], which resulted in similar onset latencies to other sentences that contained the same number of phonological words, even if they contained fewer lexical or content words. Cliticisation was retained in the online task results, with speakers preferring to delay articulation before the initial phonological word [Ik zoek het] was ready. Crucially, the structures that predicted the onset latencies were always phonological in shape, regardless of the type of task (online or delayed).

In this section, we discussed the planning of simple lexical words along with encliticisation of weakly stressed function words. Theoretical and experimental literature provide evidence that encliticisation leads to the creation of phonological words which may result in mismatch between syntactic and phonological structure (e.g. drinka pint vs. drink a pint). Phonological encoding evidence suggests that the encliticised phonological word is treated as a single lexical word in planning. The question now arises as to the way in which multiword utterances such as compounds and phrases are treated in production planning.

\section{Multiword utterances: compounds and phrases}

Both compounds and phrases have received a great deal of attention (cf. Chomsky \& Halle, 1968; Ladd, 1984; Cinque, 1993; Fabb, 1998; Badecker, 2001; Booij, 2005; Fiorentino \& Poeppel, 2007). Compounds contain two (or more) lexical words (e.g. blackboard), which means they also contain two phonological words. Recall that a lexical word is a well-formed semantic and syntactic unit that can stand on its own, be uttered in isolation, and even be considered a full utterance. Therefore, by definition, each constituent of a compound word can be a single lexical word. Furthermore, when treated as individual units, black and board are separate phonological units with their own stress assignment. When compounded, however, the units become one phonological word (bláckbòard) with a main stress falling on the first unit and a secondary stress on the second. In essence, the two independent phonological words recursively form a single phonological word. The following examples clarify the distinction between a compound and a phrase.

\begin{tabular}{|c|c|c|c|}
\hline (4) st & ture of the compound blackboard (a board u & & \\
\hline$(4 a)$ & syntactic structure: $\left[[\text { black }]_{\text {Adj }}[\text { board }]_{N}\right]_{N}$ & & \\
\hline$(4 b)$ & phrase stress: & $\mathrm{X}$ & \\
\hline & p-word stress: & $\mathrm{X}$ & $\mathrm{x}$ \\
\hline & prosodic structure: $\left((\text { bláck })_{\omega}(\text { boàrd })_{\omega}\right)_{\omega}$ & & \\
\hline $\begin{aligned} &(5) \text { st } \\
& \text { blac }\end{aligned}$ & ture of the adjective-noun phrase black boa & ain & \\
\hline$(5 a)$ & syntactic structure: $\left[[\text { black }]_{\mathrm{Adj}}[\text { board }]_{\mathrm{N}}\right]_{\mathrm{AP}}$ & & \\
\hline$(5 b)$ & phrase stress: & & $\mathrm{X}$ \\
\hline
\end{tabular}

p-word stress: $\mathrm{X} \quad \mathrm{X}$

prosodic structure: ((blàck) $\omega_{\omega}$ (boárd $\left.)_{\omega}\right)$

The structures in (4) and (5) reveal that compounds and phrases are similar on one level but are quite different on others. For instance, both structures include independent lexical words, which, by definition, are also phonological words. However, a compound is constructed by recursive word formation and on the surface it is a single phonological word, while an adjectival phrase constitutes two separate phonological words that combine to form a phonological phrase. In terms of metrical prominence, the main stress for a compound is on the initial phonological word (Example 4b) while for a phrase it is on the second element (Example 5b) (cf. Liberman \& Prince, 1979). Because the second syllable in a compound still carries stress, it cannot be considered prosodically-deficient like the determiners and auxiliaries we saw in examples (2) and (3). Note also that the syntactic head is the same for both, viz. board.

In addition to theoretical analyses of compounds and phrases, psycholinguistic studies have also addressed these issues. Much of the existing literature on the production of multiword structures focuses on the minimal planning unit (MPU), that is, the minimal unit that needs to be encoded before the speaker begins articulation. Studies are divided over advance planning and the minimal planning unit: Schriefers and Teruel (1999) found that naming latencies were shorter for phrases only when a distractor word was related to the first word of a phrase in a picture-word interference task. Conversely, Costa and Caramazza (2002) found that native Spanish speakers, when producing phrases containing post-nominal adjectives (e.g. la casa azul, "the blue house"), exhibited phonological facilitation of the adjective despite its post-position. Likewise, Jescheniak et al. (2003) found that the presentation of phonological distractor words related only to the noun caused inhibition in German adjective noun phrases (e.g. der rote Tische, "the red table"). Janssen and Barber (2012) argued that results from two picture-naming and interference tasks indicated that naming latencies were affected only by the frequency of the entire phrase ("token phrase frequency", which they drew from number of hits on Google), rather than individual word frequency. More recently, Lange and Laganaro (2014) elicited evidence that only the first word of a French adjective-noun phrase (e.g. grand chat, "large cat") was primed by a phonologically-related distractor word during picture-word interference; no effect was found when the second word in the phrase was primed. In an ERP study using picture naming, Lange, Perret, and Laganaro (2015) found that response latencies were significantly longer for adjectival phrases than simple nouns. Thus, the evidence for the phonological encoding of noun phrases and compounds is mixed in distractor tasks.

Simple naming tasks have elicited more uniform results for the production of adjective-noun phrases: in Wheeldon and Lahiri (2002), results from a prepared speech production task indicated that Dutch speakers showed sensitivity in naming latencies when the prosodic unit changed size, rather than the lexical or syllabic unit. Noun-noun compounds (e.g. ooglid, 'eyelid') elicited significantly shorter onset latencies than adjective- noun phrases (e.g. oud lid, 'old member'). Speakers took significantly longer to plan utterances containing adjective-noun phrases. Furthermore, the latencies for the compounds were similar to monomorphemic words (e.g. orgel, 'organ'). This supports evidence from a delayed naming task run by Inhoff, Briihl, and Schwartz (1996), who also found that naming latencies for English compounds were nearly identical (434 ms) to monomorphemic words (433 ms).

More recently, Jacobs and Dell (2014) conducted a series of implicit-priming tasks that tested the production of simple words, 
phrases, and nominal compounds; their findings suggested that compounds had priming behaviour similar to the monomorphemic words. That is, the onsets of the second unit of nominal compounds did not receive priming (e.g. the /d/ in sawdust); although the same word did when used in an adjective-noun phrase (e.g. grey dust).

From the evidence above it seems that compounds and phrases do differ in production planning and that compounds pattern with monomorphemic words. However, although the theoretical analysis suggests that the phonological status of compounds and phrases differ, there is no experimental evidence that the single phonological word status of compounds is similar to that of monomorphemic words. For instance, as we have seen above, phonological encliticisation of weak function words is the norm in Germanic languages (e.g. drinka pint vs. drink a pint). If compounds have the same status as single lexical words, they should also be subject to encliticisation and thereby further resort to recursive word formation. This would lead to an encliticised compound becoming even longer which in turn should have an effect on production latencies. We lay out our predictions below.

\section{Predictions}

First, although compounds and monomorphemic words pattern in the same way in a variety of tasks (Wheeldon \& Lahiri, 1997, 2002; Dell \& Jacobs, 2014), nevertheless if the compound is indeed a single recursively-structured prosodic unit, it must contain at least two syllables. Thus the size of the first phonological word will always be larger when it is a compound, as compared to a phrase where the adjective could be a single syllable: e.g. blackboard vs. black board. Moreover, a compound would also be larger than a monosyllabic monomorphemic word. Consequently, a task where latencies would be affected by the size of the first prosodic unit should find a difference between compounds on the one hand versus an adjective phrase consisting of a monosyllabic adjective and a monosyllabic single word.

Second, equally valid would be the assumption that encliticisation of these unstressed elements will lead to recursive word formation, as clitics attach to any stressed element: main or secondary. What we would like to argue here is that the assumption that a compound word behaves as one prosodic unit has other consequences. Namely if it is one prosodic unit it should be able to undergo encliticisation and again recursively become a single prosodic unit. If this is indeed the case then, independent of the size of the compound, an enclitic would again recursively make the compound into one prosodic unit. Therefore, the utterance $a$ blackboard would also be a single phonological word because, although the determiner $a$ is an important syntactic unit, it attaches to blackboard as a weak phonological unit. Thus, the appropriate phonological structure of the utterance "blackboards are heavy" would be as in (6):

\section{(6) Blackboards are heavy}

(a) Lexical grouping:

(b) Phonological grouping:

[blackboards $]_{\mathrm{N}}\left[\right.$ are $_{\mathrm{v}}$ heavy $\left.\mathrm{Adj}_{\mathrm{j}}\right]$

((bláck) $)_{\omega}$ (boàrds $\left.)_{\omega}\right)_{\omega}$ are $)_{\omega}$ (heavy)

The prediction is different for an adjective noun phrase, which contains two separate prosodic units: in these items, encliticisation (often auxiliary or any other item following the noun) would only encliticise to the second element and never to the first. The first element (the adjective) would be unaffected. That is to say, the initial prosodic unit would remain untouched and the second element that would grow with encliticisation as in example 7 below.

Black boards are heavy.

(a) Lexical grouping: $\left[\text { black }_{\text {Adj }} \text { boards }\right]_{\mathrm{N}}\left[\operatorname{are}_{\mathrm{V}}\right.$ heavy $\left._{\text {Adj }}\right]$

(b) Phonological grouping: (bláck) $)_{\omega}(\text { (boàrds })_{\omega}$ are $)_{\omega}$ (heavy)

These are the central predictions that we will test in this paper. We report four experiments that were designed to elicit information about how speakers plan multi-word utterances in English during the phonological encoding process. Following the work by Wheeldon and Lahiri (1997, 2002), we investigated naming latencies in both delayed and online tasks for English noun- noun compounds, adjective-noun phrases, and two types of monomorphemic words.

The experiments were arranged into two groups. The first group (Experiments 1 and 2) tested our first prediction; namely that compounds and phrases are treated differently in English spoken word production. Experiment 1 presented the four conditions (compounds, phrases, simple words with initial stress, and simple words with final stress) in a delayed naming task. While we have seen some evidence for the prosodic structure of compounds and phrases in picture-word interference tasks (e.g. Lange \& Laganaro, 2014) and phonological distractor tasks (Dell \& Jacobs, 2014), this experiment was designed to elicit further evidence via a simple production task. The experiment used the same design as in Wheeldon and Lahiri (2002) to confirm how English compounds and phrases are planned when speakers have time to prepare their utterances in full. Visual targets were followed by an auditory cue, after which speakers were given time to respond using the targets they saw. Following results from previous studies, the latency to begin speaking here should be determined by the total number of prosodic units in the utterance. That is, if compounds are indeed treated as single prosodic units, then they should pattern with monomorphemic words. Namely we predict that utterances containing adjective-noun phrases will elicit longer reaction times, while utterances containing compounds will pattern similarly to monomorphemic words regardless of stress assignment.

Experiment 2 presented four conditions (compounds, phrases, simple disyllabic words with initial stress, and simple monosyllabic words) in an online naming task. In Section 1.3, we discussed experimental evidence for the flexibility of the planning scope. We know that the response times in this type of priming task is affected only by the size of the first prosodic unit (not the number of prosodic units) since this is all that the speaker has time to plan for (Wheeldon \& Lahiri, 1999, Experiment 4). For this reason, in addition to the delayed task we tested how speakers planned multi-word utterances when they have no time to prepare. Here we predict that adjective-noun phrases will elicit shorter reaction times because the speaker will only wait until the first component (the adjective) is encoded before initiating speech. Conversely, compounds will take longer in this task, as we predict that speakers will treat them no differently than a disyllabic monomorphemic word.

The second group of experiments (Experiments 3 and 4) tests our second prediction: the phonological planning of compounds and phrases with clitics in delayed and online task conditions. We hypothesised that, if speakers plan compounds as single phonological units, then it follows that clitics should attach to compounds in the same way as they attach to monomorphemic words. That is, if function words that follow compounds are encliticised, then they would form a single unit; in contrast, a function word should only encliticise to the second element of a phrase. 
Experiment 3 followed the delayed task design of Experiment 1, giving speakers time to prepare their utterances before initiating speech. To encourage connected speech and encliticisation, this task involved longer utterances and more complex structures. Thus, the responses contained sentences such as "dishcloths are clean" (compound), "green yards are clean" (phrase), and "grapes are clean" (monosyllabic simple word). In this task, we predict that utterances containing cliticised compounds will elicit shorter reaction times than those containing adjective-noun phrases, reflecting the total number of prosodic words in the utterance.

The online version of this study (Experiment 4) allowed us to test encliticisation: that is, whether the word "are" in the utterances is reducing and attaching leftwards to a neighbouring word rather than to the right. As we saw from Experiment 2, naming latencies reflected the size of the first prosodic word when speakers had less time to plan; if "are" is encliticised (i.e. attached leftwards), the size of the initial prosodic unit would be larger which would be reflected in the response latencies. The key hypothesis here is that phrases would elicit significantly shorter naming latencies compared to all other conditions since speakers are required only to encode the first prosodic unit (the adjective consisting of one syllable). In contrast, compounds and disyllabic words should elicit the longest naming latencies because the compound-plus-clitic and the disyllabic word plus clitic would both contain three syllables. Under this hypothesis, monosyllabic words, on the other hand, should be significantly longer than phrases since the clitic is expected to attach to it resulting in a prosodic unit of two syllables.

\section{Experiment 1}

Experiment 1 used a delayed speech task to test whether native speakers of British English planned noun-noun compounds as single prosodic units during the phonological encoding process.

\section{Method}

\section{Materials}

The experimental materials were constructed from 60 items (e.g. groundhog), 15 per condition type. Four experimental conditions were distinguished: noun-noun compounds, adjective- noun phrases, disyllabic initially-stressed morphologically-simple words, and disyllabic final-stressed morphologically-simple words (see Table 1 for examples of responses and Appendix A for the full list of items). The compound targets consisted of semantically-transparent noun-noun compounds only, in order to remove any effect of opacity in the tasks. Two groups of disyllabic words were chosen as control conditions to test for any effect of stress pattern on naming latencies. Words were arranged into five sets beginning with one of five phonemes: /d/, /g/ , /n/, /1/, and /b/. These phonemes were chosen in order to more easily identify boundaries during analysis. 9 morphosyntactically-simple disyllabic filler words were included as well. These served to mask the pattern of manipulation between morphosyntactically-complex and morphosyntactically-simple words.

Table 1

Experimental condition types and sample responses.

\begin{tabular}{lll}
\hline & Condition type & Sample response \\
\hline 1 & Noun-Noun Compound & It was daytime. \\
2 & Adjective-Noun Phrase & It was dark time. \\
3 & Stress Initial Simple Word & It was denim. \\
4 & Stress Final Simple Word & It was decree. \\
\hline
\end{tabular}

Word familiarity was confirmed by rating data from 35 participants using a native speaker judgement task. The task contained the 60 experimental items along with filler words. Participants were asked to rate each word according to their familiarity with the word on a scale from 1 to 5, where 1 represented "not at all familiar" and 5 represented "extremely familiar". The mean judgement ratings for each condition (compounds, phrases, disyllabic initially-stressed words, and disyllabic final-stressed words) did not significantly differ from each other $(p=0.12)$. The stress of the compounds, disyllabic initially- stressed words and disyllabic final-stressed words was confirmed by 35 native Southern British English participants with questionnaires. These questionnaires presented the experimental items from the compound, disyllabic initially-stressed, and disyllabic final-stressed word conditions, along with filler words. Participants were asked to select which syllable of the word received the most stress, with the options "first", "second", and "not sure". Speaker judgements for the target items were generally strong, with all items rating at least $80 \%$ for correct stress.

The individual morphemes of compounds and phrases were also matched for a number of factors that could affect lexical recognition: word-length (number of letters), imageability, and frequency measures (simple CELEX frequency, written, and spoken counts per million as well as log frequency) (see Table 2 for means of these variables). As part of our analysis, we extracted frequencies for each unit of the compound and phrase target words, as well as the frequency of the compounds as wholes. The first morpheme of the compound (e.g. ground) was matched for length and frequency to the adjective of the phrasal condition (green). Within the compound target group, the initial compound unit contained the same form for each phoneme-organised set: e.g. (DAYbreak, DAYtime, DAYlight). The second morpheme of the compound condition was identical to the second morpheme of the phrasal condition (e.g. groundHOG and green $H O G$ ). The phrases were also constructed in such a way to discourage speakers from compounding the two words in the phrase: therefore, they contain some unique combinations, such as long jaw and green hog. This also meant that the words in our phrases would have extremely low co-occurrence frequencies.

\section{Design}

The experiment was designed using E-Prime 2.0 software. There were 9 blocks of 21 trials in total (189 items total including filler words) with optional breaks between the blocks. Items were distributed pseudo-randomly within the blocks, and three different versions of the experiment were presented. Each experimental word was presented once at each preparation latency: $800 \mathrm{~ms}, 1200 \mathrm{~ms}$, and $1400 \mathrm{~ms}$. Therefore, each word appeared three times over the experiment.

Table 2

Means of variables for the experimental words (Comp 1 and Comp 2 refer to the first and last unit of the compound, Comp is the simple compound frequency).

\begin{tabular}{lllllllll}
\hline & Comp & Comp & & & & Sim & Sim & \\
Variable & 1 & 2 & Comp & Adj & $\mathrm{N}$ & Ini & Fin & Mono \\
\hline CELEX freq & 291.5 & 258 & 5.3 & 298.7 & 259 & 2.9 & 3.2 & 19.6 \\
$\begin{array}{l}\text { CELEX } \\
\quad \text { written }\end{array}$ & 299.6 & 259.2 & 5.7 & 301.8 & 259.2 & 2.8 & 3.3 & 19.7 \\
CELEX & 187.1 & 243.2 & 1.3 & 258.9 & 243.2 & 2.4 & 1.6 & 19.7 \\
$\quad$ spoken & & & & & & & & \\
Log Freq & 2.1 & 1.6 & 0.5 & 2.4 & 1.6 & 0.5 & 0.5 & 1 \\
Imageability & 568.4 & 366.1 & 78 & 541 & 366.1 & 160.2 & 236.1 & 288.3 \\
No. of letters & 4.4 & 3.8 & 8.2 & 4 & 3.8 & 5.9 & 6.5 & 4.1 \\
\hline
\end{tabular}




\section{Procedure}

Participants were tested individually. They were seated in a sound-attenuated room facing a Dell laptop, wearing headphones that contained a microphone. They were told that they would see words on the screen, then hear the question, "What was it?". The experimental question was recorded in a soundproofed booth by a male Southern British English speaker. The participants were asked to prepare the response as fully and naturally as possible. Before the experimental trials began, they completed a set of five practice trials.

Each trial began with a blank screen, shown for $500 \mathrm{~ms}$. Then a fixation cross appeared centred on the screen for $500 \mathrm{~ms}$. After the fixation cross disappeared, the target item was shown centred on the screen for $500 \mathrm{~ms}$. Target words were presented in lowercase, black 18-point Courier New font on a white screen. The word then disappeared from the screen and the participant immediately heard the experimental question, "What was it?" through headphones. Then three beeps of equal duration were heard: the first occurred $2 \mathrm{~s}$ after the offset of the word, the next $1 \mathrm{~s}$ later, and the final beep occurred at a variable latency $(800 \mathrm{~ms}, 1200 \mathrm{~ms}$, or $1400 \mathrm{~ms})$ from the offset of the second beep. These variable latencies were chosen in order to prevent participants from guessing when the prompt would occur, and falling into patterns. Participants were instructed to answer as quickly as possible after the third beep.

\section{Participants}

Eighteen participants between the ages of 18 and 26 took part in Experiment 1. Participants were monolingual speakers of Southern British English. They were recruited through mailing lists at the University of Oxford and were compensated for their participation.

\section{Analyses}

Participants' responses were recorded as audio files on a Sony DTC-100 ES DAT- recorder. Response latencies were measured from the offset of third beep to the onset of the response (e.g. "it was daytime"). Initial measurements were made using Voicekey software designed by Henning Reetz, which automatically calculated and labelled speech onsets. The software generated time-marks for the speech editing Praat software in a 'point-tier'. Every time-mark was then hand checked (and corrected if necessary) by an impartial coder.

\section{Results and discussion}

\section{General analysis}

Responses that contained disfluencies, null responses (the subject said nothing), or incorrect answers were discarded from this analysis by an impartial coder. Any difference between the intended sentence and the produced sentence in lexical or syntactic structure was marked as an error. In addition, the compound "nightmare" and its matched items in conditions 2-4 were removed from the dataset from this experiment and Experiment 2. This was done in response to feedback that "nightmare" was not fully transparent in meaning and might therefore be treated differently than the other, more-transparent compounds. ${ }^{1}$ Responses uttered before the final beep in the delayed tasks were also discarded.

\footnotetext{
${ }^{1}$ All analyses were also run including 'nightmare' and there were no differences with the pattern of results reported.
}

For mean naming latencies, a mixed-effects model was used: naming latency was modelled as a function of the fixed effect factors, Condition Type (cond), Frequency (celexfreq), and Preparation Time (PT) in the delayed tasks. This was an interceptless mixed effect model such that each condition had a coefficient representing that condition's mean (technically its best linear unbiased estimate). In this model ${ }^{2}$, control variables were entered first and Preparation Time (PT) was sum-coded. Subjects and items were treated as random factors. Goodness of fit was established by normality of residuals.

We then used t-tests to preform direct pairwise conditions between all conditions. Following Baayen, Davidson, and Bates (2008), all $\mathrm{t}$-values greater than 2 were treated as significant.

Three variants of the adjective-noun frequencies were tested in the Frequency variable: the average of the two elements of the adjective-noun phrase, the first element (the adjective), and the second element (the phrase). The model also included a factor of Block (1-10), word length, prompt (for Experiments 3 and 4), and interactions of these factors with Condition, to test for effects of practice and word size over the course of the experiment. These interactions will only be reported if significant.

As part of this investigation, an error analysis was also carried out: errors were categorised as "time out" (the subject said nothing), "voice key error", "disfluency" (e.g. stuttering), "stress error" (incorrect prosody), and "wrong item". For the error analyses only subject-produced errors were included (technical errors such as voice key errors were not included in this analysis). The means of subject errors are shown in Table 3.

\section{Analysis: Experiment 1}

All data points beyond two standard deviations from the mean were counted as outliers and removed. This resulted in a loss of $9.1 \%$ of data $(4.2 \%$ of compounds, $2.7 \%$ of phrases, $3.2 \%$ of initially-stressed words, and $4.7 \%$ of finally-stressed words). The resulting mean RTs and percentage error rates for each condition and preparation time are shown in Table 3. As can be seen, on average the phrases show the longest speech onset latencies and the lowest error rate compared to all other conditions, which show only small differences to each other. This pattern is the same across all preparation latencies.

The best-fit model ${ }^{3}$ contained an interaction between Frequency and Condition and Preparation Time and Condition, and revealed a significant effect of Condition $(F=27.02, \mathrm{df}=4, p<0.0001)$. There was no interaction between Condition and Preparation Time $(F=0.96$, $\mathrm{df}=2, p=0.38$ ), nor was there any interaction between Condition and Frequency for any of the three variants we tested. The results of paired t-tests revealed significant differences in the naming latencies between phrases and compounds $\left(t=-7.12^{*}\right)$, phrases and monomorphemic disyllabic initially-stressed words $\left(t=6.93^{*}\right)$, and phrases and monomorphemic disyllabic final-stressed words $\left(t=-5.96^{*}\right)$. There was no significant difference in naming latencies for any other comparison (all $t \mathrm{~s}<1.1$ ): compounds, monomorphemic disyllabic initially-stressed words and monomorphemic disyllabic final-stressed words all had statistically similar reaction times.

For the sake of brevity, only the first model (which included the average Frequency for the adjective-noun phrase condition) has been reported below (Table 4). An analysis of the interaction of Preparation Time and Condition revealed no effect on reaction times.

\footnotetext{
$\overline{2} \operatorname{lmer}(\mathrm{rt} \sim 0+$ celexfreq $*$ cond + PT $*$ cond $+(0 \mid$ sub $)+(1 \mid$ item $)$.

${ }^{3} \operatorname{lmer}(\mathrm{rt} \sim 0+$ celexfreq $*$ cond $+\mathrm{PT} *$ cond $+(0+$ celexfreq $+\mathrm{PT} \mid \mathrm{sub})+(1 \mid$ item $)$
} 
Table 3

Naming Latencies (in ms) and percentage error rates (in parentheses) are shown for the four conditions of Experiment 1, on average and across the three planning durations.

\begin{tabular}{llllll}
\hline & $(1)$ & $(2)$ & $\begin{array}{l}\text { (3) Initial } \\
\text { Compounds }\end{array}$ & $\begin{array}{l}\text { Phrases } \\
\text { Stress }\end{array}$ & $\begin{array}{l}\text { Stress } \\
\text { Pean Lat. } \\
(\mathrm{ms})\end{array}$ \\
\hline $\begin{array}{l}\text { PWds } \\
\text { LexWs }\end{array}$ & 1 & 2 & 1 & 1 & \\
$\begin{array}{l}\text { Syllables } \\
\text { PT }\end{array}$ & 2 & 2 & 1 & 1 & \\
$800 \mathrm{~ms}$ & $452(2.5 \%)$ & 494 & $448(2.2 \%)$ & $465(2.8 \%)$ & $465(2.3 \%)$ \\
$1200 \mathrm{~ms}$ & $443(1.7 \%)$ & $\begin{array}{c}(1.7 \%) \\
(1.7 \%)\end{array}$ & $443(2.1 \%)$ & $439(1.6 \%)$ & $450(1.8 \%)$ \\
$1400 \mathrm{~ms}$ & $440(2.5 \%)$ & $\begin{array}{c}485 \\
(0.7 \%)\end{array}$ & $435(2.3 \%)$ & $445(1.7 \%)$ & $452(1.8 \%)$ \\
$\begin{array}{l}\text { Mean Lat. } \\
(\mathrm{ms})\end{array}$ & $\mathbf{4 4 5}(6.6 \%)$ & $\begin{array}{c}\mathbf{4 8 5} \\
(4.2 \%)\end{array}$ & $\mathbf{4 4 2}(6.6 \%)$ & $\mathbf{4 4 9}(6.2 \%)$ & \\
SD & 137 & 156 & 136 & 144 & \\
\hline
\end{tabular}

Table 4

Mixed effects model of reaction time data in Experiment 1 (Type III with Satterthwaite approximation for degrees of freedom)

\begin{tabular}{lllllll}
\hline & Sum Sq & Mean Sq & NumDF & DenDF & F value & $\operatorname{Pr}(>\mathrm{F})$ \\
\hline celexfreq & 8370 & 8370 & 1 & 164.57 & 0.9388 & 0.334 \\
cond & 722963 & 240988 & 4 & 2875.02 & 27.0287 & $<2 \mathrm{e}-16^{* * *}$ \\
PT & 23248 & 11624 & 2 & 17.28 & 1.3037 & 0.2969 \\
celexfreq:cond & 17121 & 8560 & 2 & 2875.88 & 0.9601 & 0.383 \\
cond:PT & 38164 & 6361 & 6 & 2874.85 & 0.7134 & 0.6388 \\
\hline
\end{tabular}

Error rates were analysed using a generalised linear model (GLM) with a binomial distribution (link = logit). The analysis (Table 5) revealed no effect of preparation time, condition type, or block.

\section{Discussion}

In this experiment, we observed a significant effect of Condition: the size of this effect is similar (in fact, greater) to that in Wheeldon and Lahiri (2002). Adjective noun phrases resulted in reaction times that were approximately $40 \mathrm{~ms}$ longer than the compounds. A cross-analysis of the naming latencies of compounds with both types of simple disyllabic words did not result in any significant difference, suggesting that speakers planned these three groups of targets similarly. There was a significant difference in the time it took speakers to produce adjective-noun phrases in comparison with all other target words. This suggests that speakers treated the phrases as two discrete phonological units, and crucially, they also treated compounds as single phonological word units for the purposes of this task.

\section{Experiment 2}

Experiment 1 provides evidence that, prior to articulation, speakers plan compound words as single phonological words when they

Table 5

Generalised linear model of error data in Experiment 1 (family $=$ binomial, link $=$ logit).

\begin{tabular}{llll}
\hline & Estimate & SE & z Score \\
\hline $\begin{array}{l}\text { Preparation time } \\
\text { (Intercept) }\end{array}$ & -3.13050 & 0.28092 & -11.14 \\
PT & 0.08661 & 0.13320 & -0.65 \\
Condition type & & & \\
(Intercept) & -3.27002 & 0.23504 & -13.913 \\
Cond & -0.01324 & 0.08860 & -0.149 \\
Block & & & \\
(Intercept) & -3.277186 & 0.231794 & -14.138 \\
Block & -0.004861 & 0.041422 & -0.117 \\
\hline
\end{tabular}

are given time to prepare their utterances. But these results only tell us about phonological encoding under delayed planning conditions. What happens when planning time is taken away? Will speakers sacrifice utterance initiation speed in order to encode a fully-formed unit?

Despite evidence that speech production is affected by elimination of planning time, relatively few production studies run their experimental tasks in both delayed and online task conditions. Wheeldon and Lahiri (1997) found that Dutch speakers took significantly longer to produce sentences containing clitics when they presented their task in online naming conditions. This suggested that speakers prepared the first phonological word before articulation, and that response time was affected by the size and complexity of that unit. They also found that participants preferred to construct well-formed phonological words even at the cost of utterance initiation speed. Lange and Laganaro (2014) ran an online picture-word interference task using French noun phrases, such as (e.g. grand chat, "large cat"). They found that only the first element of the phrase was primed by a phonologically related distractor; no priming effect was found when the second element in the phrase was primed. Based on this evidence, they concluded that the unit of planning displayed flexibility, yet remained a well-formed phonological word.

We hypothesise that the naming latencies of the native English speakers will reflect only the first prosodic unit of the utterance. The latencies will differ depending on the size and complexity of this initial unit. If speakers continue to plan well-formed phonological words even under online conditions, the naming latencies for compounds should reflect a single phonological word unit.

\section{Method \\ Materials}

The aim of Experiment 2 was to test whether removing the preparation time in Experiment 1 would affect post-lexical encoding of compound words. Therefore, Experiment 2 presented almost identical experimental items to Experiment 1. Because we hypothesise that only the first unit of the target will determine the production latency, we had to ensure that the control conditions contained corresponding structures. Therefore, four experimental conditions were again distinguished: noun-noun compounds, adjective-noun phrases, disyllabic morphologically-simple words, and monosyllabic morphologically-simple words (see Table 6 for examples and Appendix B for the full list of items). High-frequency monosyllabic words were chosen for Condition 4 due to the high frequencies of the adjectives in the adjective-noun phrases. 15 disyllabic filler words were included as well.

\section{Design and procedure}

The design of this experiment was similar to Experiment 1 except that participants were required to perform an online production task. Therefore, there were no preparation or deadline beeps and participants were instructed to respond as quickly as possible following the auditory question. In addition, it was important in this experiment that the target words occurred sentence-initially in the participants'

Table 6

Experimental condition types and sample responses: Experiment 2.

\begin{tabular}{lll}
\hline & Condition type & Sample response \\
\hline 1 & Noun-Noun Compound & daytime \\
2 & Adjective-Noun Phrase & dark time \\
3 & Disyllabic Simple Word & denim \\
4 & Monosyllabic Simple Word & date \\
\hline
\end{tabular}


responses. Therefore, participants were instructed to produce the target word only.

\section{Participants}

Twenty participants between the ages of 18 and 26 took part in Experiment 2. Participants were monolingual speakers of Southern British English. They were recruited through mailing lists at the University of Oxford and were compensated for their participation.

\section{Analyses}

The analyses were the same as Experiment 1. Latencies were measured from the end of the [t] plosive of the auditory prompt ("What was it?") to the onset of the target's utterance.

\section{Results and discussion}

\section{RT analysis}

Measurements were undertaken in the same way as in Experiment 1. Errors resulted in a loss of $9.5 \%$ of data. All data points beyond two standard deviations from the mean were counted as outliers and removed. This, combined with the errors, resulted in a total loss of $12.4 \%$ of data ( $12.6 \%$ from compounds, $12 \%$ from phrases, $11 \%$ from disyllabic words, and $13.7 \%$ from monosyllabic words). The resulting mean RTs and percentage subject error rates are shown in Table 7.

The best-fit model ${ }^{4}$ contained an interaction between Frequency and Condition in the fixed effects $(F=74.01, \mathrm{df}=4, p<0.001)$.

The results of paired t-tests revealed significant differences in the naming latencies between phrases and compounds $\left(t=4.043^{*}\right)$, and phrases and monomorphemic disyllabic initially-stressed words $\left(t=4.412^{*}\right)$. On average the phrases and monosyllabic conditions showed the shortest speech onset latencies, similar to one another. The compound and disyllabic word conditions resulted in longer naming latencies, similar to one another as well. There was no significant difference in naming latencies for phrases and monomorphemic monosyllabic words $(t=-0.011)$. While compounds and monomorphemic disyllabic words did not differ in naming latencies $(t=0.724)$, latencies for compounds and monosyllabic words were significantly different $\left(t=-3.795^{*}\right)$. Furthermore, disyllabic simple words and monosyllabic words had significantly different latencies $\left(t=-3.964^{*}\right)$ (see Table 8).

Error rates were analysed using a generalised linear model (GLM) with a binomial distribution (link = logit). The analysis (Table 9) revealed no effect of Condition. We found that the number of errors (Figure 5.14) decreased in blocks 2 and 3, and rose in blocks 4 and 5; however no effect of Block was found in the analysis.

\section{Discussion}

As in Experiment 1, the results from Experiment 2 showed significant effects of Condition on reaction times: responses containing compounds also showed no difference in naming latencies from disyllabic, morphosyntactically-simple words. In contrast to Experiment 1, however, speakers in this task consistently took longer to produce utterances containing compounds $(262 \mathrm{~ms})$ than they took to produce the adjective-noun phrases $(223 \mathrm{~ms})$. These results are consistent with those found in Meyer and Schriefers (1991), Meyer (1996), Wheeldon and Lahiri (1997), Schriefers and Teruel (1999), and Lange and Laganaro (2014), where on-line naming latencies only

\footnotetext{
$\overline{{ }^{4} \operatorname{lmer}(\mathrm{rt} \sim 0}+$ celexfreq $*$ cond $+(0+$ celexfreq $\mid$ sub $)+(1 \mid$ item $)$
}

Table 7

Naming Latencies (in ms) and percentage error rates (in parentheses) are shown for the four conditions of Experiment 2, on average.

\begin{tabular}{lllll}
\hline & (1) Compounds & (2) Phrases & (3) Disyllabic & (4) Mono-syllabic \\
\hline PWds & 1 & 2 & 1 & 1 \\
LexWs & 2 & 2 & 1 & 1 \\
Syllables & 2 & 2 & 2 & 1 \\
Mean Lat. (ms) & $\mathbf{2 6 2}(8.3 \%)$ & $\mathbf{2 2 3}(8.6 \%)$ & $\mathbf{2 5 9}(7 \%)$ & $\mathbf{2 2 1}(14.3 \%)$ \\
SD & 96 & 90 & 97 & 82 \\
\hline
\end{tabular}

Table 8

Mixed effects model of reaction time data in Experiment 2 (Type III with Satterthwaite approximation for degrees of freedom).

\begin{tabular}{lllllll}
\hline & Sum Sq & Mean Sq & NumDF & DenDF & F value & $\operatorname{Pr}(>\mathrm{F})$ \\
\hline celexfreq & 1719 & 1719 & 1 & 22.13 & 0.22 & 0.6423 \\
cond & 1087146 & 271787 & 4 & 24.998 & 74.015 & $1.74 \mathrm{E}-13$ \\
\hline
\end{tabular}

Table 9

Generalised linear model of error data in Experiment 2 (family = binomial, link = logit).

\begin{tabular}{llll}
\hline & Estimate & SE & z Score \\
\hline $\begin{array}{llll}\text { Condition type } \\
\text { (Intercept) }\end{array}$ & & & \\
Cond & -5.0041 & 0.5675 & -8.817 \\
Block & 0.3399 & 0.1899 & 1.790 \\
(Intercept) & & & \\
Block & -4.9192 & 0.6425 & -7.657 \\
\hline
\end{tabular}

reflected the first element of adjective-noun phrases. The mean naming latency $(223 \mathrm{~ms})$ for adjective-noun phrases reflects encoding of the first phonological unit, resulting in similar naming latencies to the monosyllabic word condition ( $221 \mathrm{~ms})$ : this suggests that, when planning time was removed, speakers only encoded the first unit of the adjective-noun phrase condition prior to speech onset. Crucially, the RT data for compounds suggests that speakers waited until the entire phonological unit was ready before beginning articulation. This indicates that speakers once again treated noun-noun compounds as single phonological units, in contrast to the phrases (which were treated as separate phonological units).

\section{Interim discussion}

In Experiments 1 and 2, we found that English native speakers treat two-word compounds as single units, with RT data statistically different from that of adjective-noun phrases. In the first set of experiments (Experiments 1 and 2), we compared production latencies of utterances containing compounds to those of utterances containing syntactic phrases (adjective-noun phrases) or morphologically simple words. In the delayed task, naming latencies reflected the total number of phonological words in the utterance. Speakers took an average of $40 \mathrm{~ms}$ longer to produce utterances containing syntactic phrases than noun-noun compounds. Utterances containing compounds generated statistically similar production latencies to morphologically-simple words. Conversely, when planning time was removed in Experiment 2, latencies were only sensitive to the first phonological unit of the utterance. Both of these findings are in line with those in Wheeldon and Lahiri $(1997,2002)$.

In both Experiments 1 and 2, we saw a significant effect of Condition type on production latencies. In the delayed task (Experiment 1), compound words elicited shorter naming latencies than adjective-noun phrases, similar to those of disyllabic morphosyntactically-simple words. In this experiment, the number of syllables was held 
stant across all conditions, while the number of phonological words and lexical words, and the placement of stress all varied. Despite these variations, the only thing that reliably predicted naming latencies was the total number of prosodic units in the utterance. Although compounds contained two morphosyntactic words (and therefore two phonological words), they were treated as single prosodic units in this task, generating nearly identical naming latencies to morphosyntactically-simple words. In the online task (Experiment 2), we saw a different pattern of effects: compound words elicited longer naming latencies than phrases, similar only to those found for disyllabic morphosyntactically-simple words. Adjective-noun phrases were associated with shorter latencies in this task, similar only to those found for the monosyllabic simple words.

Experiment 2 made clear the importance of testing the stimuli in both task types: when speakers had enough time to plan, the total number of prosodic units dictated the naming latencies. When planning time was restricted, however, the phonological encoding was completed for only the first prosodic unit before articulation: this was evident in the naming latencies in Experiment 2. Crucially, speakers sacrificed utterance initiation time in order to construct well-formed prosodic units. In the case of the compound words: they did not begin speaking until the entire compound structure was encoded. While the data in Experiment 1 serves to support existing evidence for the phonological word in phonological encoding, Experiment 2 offers an important additional contribution to our understanding of this process: it reveals that speakers still preferred to plan compounds as a single prosodic structure during on-line speech production. These findings support both the theories regarding the prosodic word structure of compounds and the shape of the planning unit in the word-form encoding process.

\section{Experiment 3}

Experiments 1 and 2 have established that English speakers are treating noun-noun compounds as single phonological units. The aim of Experiment 3 and 4 is to test the limits of this hypothesis. Our theory and accompanying empirical evidence dictates that weak function words behave like clitics and will attach to a phonological word in order to form a larger recursive phonological word. Thus, the total number of phonological words would not increase with the addition of a clitic. If this is indeed the case, then clitics should attach to compound words as a whole and form a single phonological unit and the cliticised compounds will elicit production latencies similar to those of cliticised disyllabic words. Cliticised phrases will elicit longer latencies, due to the total number of phonological words in the utterance being greater than all other conditions. If, however, the clitic should only attach to the last unit of the compound, then the mean naming latencies for the compound and phrasal conditions will be the same. Note, that this experiment does not actually support encliticisation - i.e., the function word attaching leftwards; it could potentially add rightwards. The crucial test here is that the function word does not add to the number of prosodic words.

\section{Method}

\section{Materials}

In order to ensure that speakers were generating well-formed sentences, we had to present target words that would easily cliticise in plural form with the verb are, e.g. dishcloths are clean. This required a new target wordlist, with different intended utterances (see Table 10). The experimental materials were constructed from 60 items, 15 per condition type, selected from the CELEX database based on their
Table 10

Experimental condition types and sample responses: Experiment 3.

\begin{tabular}{lll}
\hline Condition type & Target & Sample sentence \\
\hline N-N Compound & dishcloths & Dishcloths are clean. \\
Adj-N Phrase & drab cloths & Drab cloths are clean. \\
Disyllabic & donkeys & Donkeys are clean. \\
Monosyllabic & drapes & Drapes are clean. \\
\hline
\end{tabular}

lexical frequency. Four experimental conditions were distinguished: noun-noun compounds, adjective-noun phrases, initially-stressed disyllabic simple words, and monosyllabic simple words (see Appendix $\mathrm{C}$ for full list of items). 10 disyllabic filler words were included as well.

A word familiarity task was run with these targets and resulted in high ratings: mean judgement ratings for each condition did not significantly differ from each other $(p=0.67)$.

\section{Design}

The experiment was designed using E-Prime 2.0 software. There were 10 blocks of 19 trials in total (190 items total including filler words) with optional breaks between the blocks. Items were distributed pseudo-randomly within the blocks, and five different versions of the experiment were presented, in which the sets of experimental questions were rotated. Each experimental word was presented once at each preparation latency: $800 \mathrm{~ms}, 1200 \mathrm{~ms}$, and $1400 \mathrm{~ms}$. Thus, each word appeared three times over the experiment.

\section{Procedure}

Participants were tested individually. They were seated in a sound attenuated room facing a Dell laptop, wearing headphones that contained a microphone. They were told that they would see words on the screen, then hear five different questions (see Appendix D).

The experimental questions were recorded in a soundproofed booth by a female Southern British English speaker. The participants were asked to prepare the response as fully and naturally as possible. Before the experimental trials began, they completed a set of five practice trials. The rest of the experimental design was identical to Experiment 1.

\section{Participants}

Twenty participants between the ages of 18 and 29 took part in Experiment 3. Participants were monolingual speakers of Southern British English. They were recruited through mailing lists at the University of Oxford and were compensated for their participation (see Table 11).

\section{Results and discussion}

\section{RT analysis}

All data points beyond two standard deviations from the mean were counted as outliers and removed. This resulted in a loss of $8.1 \%$ of data $(9.7 \%$ of compounds, $7.1 \%$ of phrases, $6.9 \%$ of disyllabic words, and $8.7 \%$ of monosyllabic words). Mean reaction times and percentage error rates for Experiment 3 are shown in Table 12.

The best-fit model $^{5}$ contained an interaction between Frequency and Condition and Preparation Time and Condition, and revealed a

\footnotetext{
${ }^{5} \operatorname{lmer}(\mathrm{rt} \sim 0+$ celexfreq $*$ cond $+\mathrm{PT} *$ cond $+(0+$ celexfreq $+\mathrm{PT} \mid$ sub $)+(1 \mid$ item $)$
} 
Table 11

Means of variables for the experimental words (Experiment 3).

\begin{tabular}{llllllll}
\hline & Comp 1 & Comp 2 & Comp & Adj & N & Di & Mono \\
\hline CELEX frequency & 130.5 & 170.4 & 0.5 & 266.6 & 170.4 & 8.4 & 10.4 \\
CELEX written & 105.8 & 169.9 & 0.5 & 269.4 & 169.9 & 8.9 & 10.8 \\
CELEX spoken & 74 & 177.2 & 0.2 & 231.2 & 177.2 & 2.2 & 4.8 \\
Log frequency & 1.7 & 1.8 & 0.1 & 2.2 & 1.8 & 0.8 & 0.8 \\
Imageability & 498.8 & 488.5 & - & 453.2 & 488.5 & 395.1 & 495.6 \\
No. of letters & 4.1 & 5.1 & 9.3 & 4.1 & 5.1 & 6.2 & 4.4 \\
\hline
\end{tabular}

Table 12

Naming Latencies (in ms) and percentage error rates (in parentheses) are shown for the four conditions of Experiment 3, on average and across the three planning durations.

\begin{tabular}{|c|c|c|c|c|c|}
\hline & $\begin{array}{l}\text { (1) } \\
\text { Compounds } \\
+ \text { Clitics }\end{array}$ & $\begin{array}{l}(2) \\
\text { Phrases + Clitics }\end{array}$ & $\begin{array}{l}(3) \\
\text { Disyll + } \\
\text { Clitics }\end{array}$ & $\begin{array}{l}\text { Monosyll + Clitics } \\
\text { Mon }\end{array}$ & $\begin{array}{l}\text { Mean } \\
\text { Lat. } \\
(\mathrm{ms})\end{array}$ \\
\hline PWds & 1 & 2 & 1 & 1 & \\
\hline LexWs & 2 & 2 & 1 & 1 & \\
\hline $\begin{array}{l}\text { Syllables } \\
\text { PT }\end{array}$ & 3 & 3 & 3 & 2 & \\
\hline $800 \mathrm{~ms}$ & $343(7.3 \%)$ & $416(4.0 \%)$ & $\begin{array}{l}333 \\
(4.7 \%)\end{array}$ & $344(5.0 \%)$ & $\begin{array}{l}359 \\
(4.9 \%)\end{array}$ \\
\hline $1200 \mathrm{~ms}$ & $328(5.0 \%)$ & $394(4.3 \%)$ & $\begin{array}{l}322 \\
(4.3 \%)\end{array}$ & $325(7.3 \%)$ & $\begin{array}{l}342 \\
(5.3 \%)\end{array}$ \\
\hline $1400 \mathrm{~ms}$ & $322(6.7 \%)$ & $390(4.3 \%)$ & $\begin{array}{l}321 \\
(6.3 \%)\end{array}$ & $327(4.7 \%)$ & $\begin{array}{l}341 \\
(5.8 \%)\end{array}$ \\
\hline $\begin{array}{l}\text { Mean } \\
\text { Lat. (ms) }\end{array}$ & $331(6.3 \%)$ & $400(4.2 \%)$ & $\begin{array}{l}326 \\
(5.1 \%)\end{array}$ & $332(5.6 \%)$ & \\
\hline SD & 115 & 133 & 110 & 112 & \\
\hline
\end{tabular}

significant effect of Condition $(F=175.48, \mathrm{df}=4, p<0.001)$. There was also a significant effect of Preparation Time $(F=7.672, \mathrm{df}=2$, $p=0.003)$. There was no interaction between Condition and Preparation Time nor was there any interaction between Condition and Frequency for any of the three variants we tested.

The results of paired t-tests revealed significant differences in the naming latencies between phrases and compounds $\left(t=-18.05^{*}\right)$, phrases and monomorphemic disyllabic initially-stressed words $\left(t=-17.55^{*}\right)$, and phrases and monomorphemic monosyllabic words $\left(t=-16.30^{*}\right)$. There was no significant difference in naming latencies for any other comparison (all $t \mathrm{~s}<1.8$ ): compounds, monomorphemic disyllabic initially-stressed words and monosyllabic words all had statistically- similar reaction times. Preparation time was significant in this experiment, but there was no interaction between any of the conditions and preparation time in the analysis. The results also revealed an effect of block on reaction times: latencies were significantly faster in Block 10 than Block $1\left(\mathrm{t}=-2772^{*}\right)$; however, there was no interaction of Condition and Block on naming latencies. There was no effect of word length or prompt type (see Table 13).

The error rates were analysed using a generalised linear model (GLM) with a binomial distribution (link=logit). This analysis

Table 13

Mixed effects model of reaction time data in Experiment 3 (Type III with Satterthwaite approximation for degrees of freedom)

\begin{tabular}{lllllll}
\hline & Sum Sq & Mean Sq & NumDF & DenDF & F value & $\operatorname{Pr}(>\mathrm{F})$ \\
\hline celexfreq & 1399 & 1399 & 1 & 51.1 & 0.353 & 0.555183 \\
cond & 2087467 & 695822 & 4 & 53.0 & 175.487 & $<2.2 \mathrm{e}-16$ \\
PT & 60843 & 30422 & 2 & 18.9 & 7.672 & 0.003649 \\
block & 69061 & 7673 & 9 & 2736.71 & 1.935 & 0.043 \\
celexfreq:cond & 1912 & 956 & 2 & 52.1 & 0.241 & 0.78668 \\
cond:PT & 15995 & 2666 & 6 & 3164.9 & 0.672 & 0.672096 \\
cond:block & 94255 & 3491 & 27 & 2717.54 & 0.880 & 0.642567 \\
\hline
\end{tabular}

(Table 14) revealed a weak effect $\left(\mathrm{z}=2.016^{*}\right)$ of Condition on error rate. There was no effect of PT or Block on error rates.

\section{Discussion}

In this experiment, we observed a significant effect of Condition: the size of this effect is similar to that in Experiment 1. Cliticised adjective-noun phrases resulted in the longest mean naming latency (400 ms), while cliticised compounds elicited a much shorter mean latency $(331 \mathrm{~ms})$. This finding was consistent with the results from Experiment 1 , which indicated that speakers were planning compounds and phrases differently. Naming latencies for the clitic + compound condition were much shorter, similar to those for both morphologically-simple word conditions.

\section{Experiment 4}

Experiment 4 presents the target words of Experiment 3 in online task conditions. We saw in Experiment 2 that planning time affected phonological encoding: under restricted planning, speakers only encoded the first phonological unit of the utterance. For compounds, this was the entire recursive unit; for phrases, this was only the first phonological unit (the adjective). Based on our earlier hypotheses, we predict that clitics will behave no differently in online task conditions: they will still attach to compounds and form a larger phonological word. Because naming latencies only reflect encoding of the first phonological unit, the latencies for adjective-noun phrases will only reflect encoding of the adjective. This will result in significantly shorter latencies than all other conditions, including the monosyllabic word condition.

\section{Method}

The materials and design were identical to those used in Experiment 3 . The procedure was altered to an online production task. Participants were instructed to respond as quickly as they could, following the auditory question.

\section{Participants}

Twenty-five participants between the ages of 18 and 26 took part in Experiment 4. Participants were monolingual speakers of Southern British English. They were recruited through mailing lists at the University of Oxford and were compensated for their participation.

\section{Results and discussion}

\section{RT analysis}

Data trimming treated all data points beyond two standard deviations from the mean as outliers: this resulted in the removal of 56 data points $(4.3 \%$ of compounds, $3.2 \%$ of phrases, $2.7 \%$ of disyllabic words, and $4.8 \%$ of monosyllabic words). The total loss made up only $3.8 \%$ of data. The resulting mean RTs and percentage error rates are shown in Table 15.

As can be seen, on average the phrasal condition elicited the shortest speech onset latencies. The latencies for the monosyllabic word condition were longer, averaging $208 \mathrm{~ms}$, and the latencies for the phrasal and disyllabic word conditions were the longest.

The best-fit model ${ }^{6}$ contained Frequency, Prompt, and Condition in the fixed effects. There was a significant effect of Condition $(F=21.21, \mathrm{df}=4, p<0.001)$ and a weak effect of Prompt $(F=2.75$,

\footnotetext{
${ }^{6} \operatorname{lmer}(\mathrm{rt} \sim 0+$ prompt $*$ cond + celexfreqsc $*$ cond $+(0+$ prompt $\mid$ sub $)+(1 \mid$ item $)$
} 
Table 14

Generalised linear model of error data in Experiment 3 (family = binomial, link = logit).

\begin{tabular}{llll}
\hline & Estimate & SE & z Score \\
\hline $\begin{array}{l}\text { Preparation time } \\
\text { (Intercept) }\end{array}$ & -2.69856 & 0.29301 & -9.21 \\
PT & -0.07687 & 0.13874 & -0.554 \\
Condition type & & & \\
(Intercept) & -2.48357 & 0.20368 & -12.194 \\
Cond & -0.1721 & 0.08538 & $-2.016^{*}$ \\
Block & & & \\
(Intercept) & -2.58408 & 0.20802 & -12.422 \\
Block & -0.05294 & 0.03659 & -1.447 \\
\hline
\end{tabular}

Table 15

Naming Latencies (in ms) and percentage error rates (in parentheses) are shown for the four conditions of Experiment 4, on average.

\begin{tabular}{lllll}
\hline & (1) Compounds & (2) Phrases & (3) Disyllabic & (4) Mono-syllabic \\
\hline PWds & 1 & 2 & 1 & 1 \\
LexWs & 2 & 2 & 1 & 1 \\
Syllables & 2 & 2 & 2 & 1 \\
Mean Lat. (ms) & $\mathbf{2 1 5}(4.2 \%)$ & $\mathbf{1 9 0}(3.2 \%)$ & $\mathbf{2 2 2}(4.0 \%)$ & $\mathbf{2 0 8}(4.3 \%)$ \\
SD & 67 & 63 & 64 & 66 \\
\hline
\end{tabular}

$\mathrm{df}=5, p=0.042$ ). There was no interaction between any of the variables and Condition (see Table 16).

The results of paired t-tests revealed significant differences in the naming latencies between phrases and compounds $\left(t=8.51^{*}\right)$, and phrases and monomorphemic disyllabic initially-stressed words $\left(t=5.54^{*}\right)$. Additionally, naming latencies for phrases and monosyllabic words were significantly different $\left(t=3.56^{*}\right)$. Latencies for compounds and disyllabic words were not different $(t=1.29)$, but compounds and monosyllabic words were significantly different $\left(t=-4.27^{*}\right)$. Furthermore, disyllabic simple words and monosyllabic words had significantly different latencies $\left(t=-2.21^{*}\right)$.

The error rates were analysed (Table 17) using a generalised linear model $(\mathrm{GLM})$ with a binomial distribution (link $=$ logit). There was a weak effect $\left(z=-2.085^{*}\right)$ of Condition on errors, with Condition 4 eliciting more errors $\left(z=-2.055^{*}\right)$ than other conditions. Block did not affect error rate $(z=-0.466)$.

Table 16

Mixed effects model of reaction time data in Experiment 4 (Type III with Satterthwaite approximation for degrees of freedom).

\begin{tabular}{lllllll}
\hline & Sum Sq & Mean Sq & NumDF & DenDF & F value & $\operatorname{Pr}(>\mathrm{F})$ \\
\hline prompt & 19161 & 4790 & 5 & 38.27 & 2.751 & 0.04187 \\
cond & 110836 & 36945 & 3 & 48.13 & 21.2169 & $6.72 \mathrm{E}-09$ \\
celexfreqsc & 2363 & 2363 & 1 & 50.69 & 1.357 & 0.24951 \\
prompt:cond & 23562 & 1964 & 12 & 1237.33 & 1.1276 & 0.33295 \\
cond:celexfreq & 3310 & 1103 & 3 & 47.98 & 0.6337 & 0.59691 \\
\hline
\end{tabular}

Table 17

Generalised linear model of error data in Experiment 4 (family $=$ binomial, link = logit).

\begin{tabular}{llll}
\hline & Estimate & SE & z Score \\
\hline $\begin{array}{llll}\text { Condition type } \\
\text { (Intercept) }\end{array}$ & -2.62963 & 0.20017 & -13.137 \\
Cond & -0.19176 & 0.09196 & $-2.085^{*}$ \\
Block & & & \\
(Intercept) & -2.89287 & 0.23073 & -12.538 \\
Block & -0.03014 & 0.06472 & -0.466 \\
\hline
\end{tabular}

\section{Discussion}

In this experiment, we again observed a significant effect of Condition. Cliticised adjective-noun phrases resulted in the shortest mean naming latency $(203 \mathrm{~ms})$, while cliticised compounds elicited a much longer mean latency $(234 \mathrm{~ms})$. A cross-analysis of the naming latencies for compound + clitic condition only showed a statistically-significant result for the disyllabic control condition. The mean naming latency for the monosyllabic word + clitic condition (208 ms) was significantly faster than either the disyllabic (222 ms) or compound condition (215 ms). Adjective-noun phrases were faster yet, with a mean naming latency of $190 \mathrm{~ms}$ (see Table 18)

\section{General discussion}

Classic language production models (Levelt, 1989; Levelt et al., 1999; Roelofs, 1997) do not assume a lexically-shaped unit as the minimal underlying representation during phonological encoding. Both have agreed that the unit being prepared at this stage is the phonological word (rather than the lexical word), which is generated from metrical information retrieved from the lexicon according to the phonological rules of the language. Our study supports the claim that the phonological word is the unit of phonological encoding, as our data confirm that when planning an utterance, the crucial unit can be more than a lexical word; it can be in fact a lexical word accompanied by a phonologically weak element such as determiners and prepositions.

In this study, we have also shown that metrical information alone is not sufficient for determining the units of prosodification. Our studies have gone beyond single lexical items and compounds, which are composed of at least two stressed lexical items e.g. dóghòse, compared to a two word phrase, which also has two stressed lexical items, e.g. dàrk hóuse. Our question was: is doghouse treated the same way as dark house during phonological encoding or is it treated the same way as dóg? As we argued above, lexically doghouse is one prosodic unit indistinguishable from $\operatorname{dog}$ and indeed dogmatic despite its metrical similarity to dark house. This is because phonological words are built recursively and they are the largest phonological unit that is fed into post-lexical phonological encoding processes.

It therefore follows that post-lexical phonological processes should allow unstressed items to cliticise to compounds as a whole in the same way as with monomorphemic lexical items. In contrast the same unstressed items will cliticise to only the last element of a phrase (e.g. house in our example above). No current model of language production makes this distinction between lexical and postlexical prosodic processes.

We ran a delayed speech production task based on Sternberg et al. (1978) and modelled after Wheeldon and Lahiri (2002) to test prosodification in English. We compared naming latencies for noun-noun compounds, adjective-noun phrases, and monomorphemic nouns and found that naming latencies for the compounds were significantly shorter than the phrases, and similar to the latencies for the monomorphemic words. Speakers took an average of $40 \mathrm{~ms}$ longer to produce utterances containing syntactic phrases than noun-noun com-

Table 18

Size of the prosodic unit in Experiment 4.

\begin{tabular}{lll}
\hline Condition & First PWd unit & Size of first PWd unit \\
\hline Compound + Clitic & (doorways are) & $(\sigma \sigma \sigma)$ \\
Adj-N + Clitic & $(\text { dark })_{\omega}$ & $(\sigma)$ \\
Disyllabic + Clitic & $($ donkeys are) & $(\sigma \sigma \sigma)$ \\
Monosyllabic + Clitic & $(\text { dates are) })_{\omega}$ & $(\sigma \sigma)$ \\
\hline
\end{tabular}


pounds. Utterances containing compounds generated statistically similar production latencies to morphologically-simple words. This suggested that English speakers behave the same as those in the other studies. However, evidence from online planning experiments (cf. Wheeldon \& Lahiri, 1997) indicate that the shape of the planning unit might change under different task conditions. Consequently, we ran an online version of the production task in Experiment 1: here we found that English speakers still planned prosodic units during online planning. As before, latencies for this task revealed sensitivity to the first phonological unit of the utterance. Both of these findings are in line with those in Wheeldon and Lahiri (1997) and Wheeldon and Lahiri (2002). We recognise that this task still allowed for a certain amount of planning prior to utterance initiation; there was the possibility that the time between the visual target and the auditory prompt would have removed any effect of on-line planning. However, the results were significantly different to those found in Experiment 1. Furthermore, in Experiment 4, the prompt was not simply "what was it?". Participants saw the target word(s) then heard one of five prompts related to the target such as, "what are clean" or "what are good"? Therefore, they would not be able to prepare their responses in full until the auditory prompt completed.

In the series of experiments reported above, we found that English native speakers treat two-word compounds as single prosodic units, with RT data statistically different than that of adjective-noun phrases. The first set of experiments established that the planning unit in English speakers was also a phonological word. Crucially, we also found that speakers treated compound words as single prosodic items, at least for the purposes of planning spoken utterances.

In order to test our second hypothesis, we introduced clitics into the utterances in Experiments 3 and 4. Experiments 3 and 4 tested naming latencies for utterances containing the original four conditions, with the added feature of an auxiliary, e.g. dishcloths are clean. We had hypothesised that, if English compounds are really acting as single, recursive prosodic units, then the auxiliary should reduce and attach leftwards to the entire unit in normal speech, e.g. dishcloths're nice. The results were consistent with those in Experiments 1 and 2: in the delayed task, utterances containing cliticised compounds elicited similar naming latencies to utterances containing morphologically-simple words; i.e. latencies for degrees're and dishcloths're were no different. However, latencies were significantly longer for the phrasal conditions as in dark cloths're.

Under online task conditions (Experiment 4), speakers once again generated similar naming latencies for utterances containing cliticised compounds to those containing cliticised disyllabic words. Latencies for the adjective-noun phrases were significantly shorter (30 ms), indicating that speakers were only encoding the first (uncliticised) unit of the phrase; i.e. dark in dark cloths're. Here, results again suggested that planning was restricted to the size of first phonological unit: in this case, naming latencies for noun-noun compounds were similar to disyllabic monomorphemic words, while adjective-noun phrases generated the shortest naming latencies (due to the fact that speakers were only accessing the first unit of the phrase- the monosyllabic adjective). Recall that the first prosodic unit in the utterance had three sizes.

The condition with the smallest phonological word (dark in the phrasal condition) generated the fastest response times, followed by the monosyllable + clitic condition (dates are), and then the two larger compound + clitic (dishcloths are) and disyllable + clitic structures (donkeys are). This suggested that the auxiliary was attaching leftwards to the entire prosodic unit of the compound, yet only attaching to the noun of the adjective-noun phrase in the phrasal condition.
The results of both groups of experiments revealed important information about phonological encoding and prosodification in native English speakers. We confirmed that speakers were indeed generating prosodic frames according to phonological, not lexical, words. Furthermore, the difference in naming latencies between compounds and phrases indicated that the prosodic frames for the complex morphosyntactic structures of compounds were constructed according to the outer, recursive phonological word structure of the compound. This is remarkable as it reveals both experimental evidence for the planning of prosodic structures in English, and evidence for the makeup of the structure itself.

Both experiments indicated that compounds were being planned as a single unit, generating significantly-different mean latencies to the adjective-noun phrases. Critically, speakers in the online tasks continued to treat compounds as single, disyllabic units, suggesting that these items retained their prosodic structure even when planning time was taken away. Taken together, the results from all four experiments indicate that compounds, which contain two morphological words and therefore two phonological words, are nevertheless treated as single prosodic units for the purposes of postlexical encoding during speech production.

In summary, our findings require the development of the classic model of phonological encoding to incorporate a distinction between lexical and postlexical prosodic processes, such that lexical boundaries have consequences for post-lexical phonological encoding.

Our claim raises many issues concerning the size of recursive structures both lexically and post-lexically. The current study has focused on constraints for minimal prosodic units at both levels. However, the issue of maximal units remains. For example, in agglutinating languages such as Turkish and Finnish, a suffixed word can easily contain six to seven syllables and even English has been claimed to have affixed words of considerable length, such as antidisestablishmentarianism (cf Payne, 2006). Similarly compounds, which are recursive in the lexicon, are not limited to the two word structures we have examined here. Theoretically, longer compounds are possible such as hazelnut-butterknife, where the structure would be as in examples $8 \mathrm{a}$ or $8 \mathrm{~b}$ :

\author{
(8) Hazelnut butterknife \\ (a) Hazelnut-butterknife (a butter knife for cutting hazel nuts): \\ $\left(\left((\text { hazel })_{\omega}(\text { nut })_{\omega}\right)_{\omega}\left((\text { butter })_{\omega}(\text { knife })_{\omega}\right)_{\omega}\right)_{\omega}$ \\ (b) Hazelnut-butterknife (a knife for spreading hazelnut butter): \\ $\left.\left(\left((\text { hazel })_{\omega}(\text { nut })_{\omega}\right)_{\omega}(\text { butter })_{\omega}\right)_{\omega}(\text { knife })_{\omega}\right)$
}

The question therefore remains, to what extent processing limitations, rather than the structure of linguistic units per se, constrain the recursivity of both lexical and postlexical prosodic units in connected speech production.

\section{Uncited references}

Anderson (2005), Bates et al. (2003, 2015, in press), Bien et al. (2005), Boersma and Weenink (2013), Collins and Loftus (1975), Davis (2005), Delazer and Semenza (1998), Dunabeitia et al. (2007), Ferreira et al. (2005), Finkbeiner et al. (2006), Fox et al. (2009), Griffin and Bock (1998), Janssen et al. (2008), Jescheniak and Levelt (1994), Jordan (1990), Levelt (1992, 2001), Liberman and Prince (1977), MacKay (1987), Mahon et al. (2007), Oldfield and Wingfield (1965), Reetz (2010), Roelofs (1992, 1993), Schneider et al. (2002), Schriefers (1992, 1993), Vigário (2010). 


\section{Acknowledgments}

The study was funded in part by the Lady Margaret Hall (Oxford) Academic Development Fund. We would like to thank Henning Reetz for designing the voice key script used to calculate naming latencies in all four experiments.

\section{A. Target items for Experiment 1}

\begin{tabular}{llll}
\hline $\begin{array}{l}\text { Noun-Noun com- } \\
\text { pounds }\end{array}$ & $\begin{array}{l}\text { Adj-N } \\
\text { phrases }\end{array}$ & $\begin{array}{l}\text { Simple initial } \\
\text { stress }\end{array}$ & $\begin{array}{l}\text { Simple final } \\
\text { stress }\end{array}$ \\
\hline daybreak & dark break & denim & default \\
daytime & dark time & debit & deceit \\
daylight & dark light & dagger & gazeelle \\
groundhog & green hog & gravel & gazette \\
groundwork & green work & griddle & guitar \\
groundnut & green nut & gravy & neglect \\
nightcap & nice cap & nibble & noblesse \\
nightgown & nice gown & nickel & notate \\
nightmare & nice mare & nitrate & lament \\
lockjaw & long jaw & locker & latrine \\
locksmith & long smith & locust & lapel \\
locknut & long nut & lodger & baboon \\
bathrobe & bad robe & banter & balloon \\
bathroom & bad room & ballad & bamboo \\
bathtub & bad tub & basil & \\
\hline
\end{tabular}

\section{B. Target items for Experiment 2}

\begin{tabular}{llll}
\hline Condition 1 & Condition 2 & Condition 3 & Condition 4 \\
\hline Compounds & Phrases & Disyllabic & Monosyllabic \\
\hline daybreak & dark break & denim & dame \\
daytime & dark time & debit & date \\
daylight & dark light & dagger & daze \\
groundhog & green hog & gravel & grease \\
groundwork & green work & griddle & greed \\
groundnut & green nut & gravy & greet \\
nightcap & nice cap & nibble & nine \\
nightgown & nice gown & nickel & Nile \\
nightmare & nice mare & nitrate & ninth \\
lockjaw & long jaw & locker & lob \\
locksmith & long smith & locust & log \\
locknut & long nut & lodger & loft \\
bathrobe & bad robe & banter & bag \\
bathroom & bad room & ballad & band \\
bathtub & bad tub & basil & bat \\
\hline
\end{tabular}

\section{Target items for Experiments 3 and 4}

\begin{tabular}{llll}
\hline Condition 1 & Condition 2 & Condition 3 & Condition 4 \\
\hline Compounds & Phrases & Disyllabic & Monosyllabic \\
\hline doorways & deep ways & daisies & doves \\
dishcloths & drab cloths & dolphins & ducks \\
dustpans & dark pans & donkeys & drapes \\
graveyards & green yards & gospels & grapes \\
grandstands & grey stands & griddles & graphs \\
grindstones & good stones & goblins & gloves \\
nightgowns & nice gowns & noodles & nuns \\
neckties & neat ties & napkins & nets \\
nightshirts & new shirts & nickels & nodes \\
lampshades & low shades & lemons & leeks \\
logbooks & late books & lanterns & lungs \\
lipsticks & large sticks & lions & lanes \\
\hline & & &
\end{tabular}

\begin{tabular}{llll}
\hline bookshops & big shops & barrels & bowls \\
bathtubs & bright tubs & blankets & blades \\
ballrooms & blue rooms & bankers & brooms \\
\hline
\end{tabular}

\section{Experimental questions and sample responses for Experiments 3 and 4}

\begin{tabular}{ll}
\hline Question & Sample response \\
\hline What are & Dustpans are good.Nice gowns are good.Lemons are good.Bowls are \\
good? & good. \\
What are & Lampshades are nice.Bright tubs are nice.Noodles are nice.Graphs \\
nice? & are nice. \\
What are & Dishcloths are clean.Green yards are clean.Napkins are clean.Lungs \\
clean? & are clean. \\
What are & Bathtubs are dry.Low shades are dry.Griddles are dry.Nets are dry. \\
dry? & \\
What are big? & Graveyards are big.New shirts are big.Barrels are big.Lanes are big. \\
\hline
\end{tabular}

\section{References}

Anderson, S.R., 2005. Aspects of the theory of clitics. Oxford University Press, USA Bayen, R., Davidson, D., Bates, D., 2008. Mixed-effects modeling with crossed random effects for subjects and items. Journal of Memory and Language 59 (4), $390-412$.

Bates, E., D’Amico, S., Jacobsen, T., Székely, A., Andonova, E., Devescovi, A., ... Gutierrez, Gabriel, 2003. Timed picture naming in seven languages. Psychonomic Bulletin \& Review 10 (2), 344-380.

Bates, D., Mächler, M., Bolker, B., \& Walker, S. (in press). Fitting linear mixed-effects models using lme4.

Bates, D., Maechler, M., Bolker, B., Walker, S., Christensen, R.H.B., Singmann, H., ... Rcpp, L., 2015. Package 'Ime4'. Convergence 12, 1.

Bien, H., Levelt, W., Baayen, R., 2005. Frequency effects in compound production. Proceedings of the National Academy of Sciences of the United States of America 102 (49), 17876-17881.

Boersma, P., Weenink, D., 2013. Praat software. University of Amsterdam, Amsterdam.

Cholin, J., Schiller, N., Levelt, W., 2004. The preparation of syllables in speech production. Journal of Memory and Language 50 (1), 47-61.

Collins, A., Loftus, E., 1975. A spreading-activation theory of semantic processing. Psychological Review 82 (6), 407.

Costa, A., Caramazza, A., 2002. The production of noun phrases in English and Spanish: Implications for the scope of phonological encoding in speech production. Journal of Memory and Language 46 (1), 178-198.

Damian, M., Dumay, N., 2007. Time pressure and phonological advance planning in spoken production. Journal of Memory and Language 57 (2), 195-209.

Davis, C., 2005. N-watch: A program for deriving neighborhood size and other psycholinguistic statistics. Behavior Research Methods 37 (1), 65-70.

Delazer, M., Semenza, C., 1998. The processing of compound words: A study in aphasia. Brain and Language 61 (1), 54-62.

Dell, G., 1986. A spreading-activation theory of retrieval in sentence production. Psychological Review 93 (3), 283.

Duñabeitia, J., Perea, M., Carreiras, M., 2007. Do transposed-letter similarity effects occur at a morpheme level? Evidence for morpho-orthographic decomposition. Cognition 105 (3), 691-703.

Ferrand, L., Segui, J., Grainger, J., 1996. Masked priming of word and picture naming: The role of syllabic units. Journal of Memory and Language 35 (5), 708-723.

Ferrand, L., Segui, J., Humphreys, G., 1997. The syllable's role in word naming. Memory \& Cognition 25 (4), 458-470.

Ferreira, F., 1993. Creation of prosody during sentence production. Psychological Review 100 (2), 233.

Ferreira, V.S., Slevc, L.R., Rogers, E.S., 2005. How do speakers avoid ambiguous linguistic expressions?. Cognition 96 (3), 263-284.

Finkbeiner, M., Gollan, T.H., Caramazza, A., 2006. Lexical access in bilingual speakers: What's the (hard) problem?. Bilingualism: Language and Cognition 9 (02), 153.

Fox, J., Bates, D., Firth, D., Friendly, M., Gorjanc, G., Graves, S., ..., \& Ogle, D. (2009). "Car": Companion to applied regression, R Package version 1.2-16.

Griffin, Z., Bock, K., 1998. Constraint, word frequency, and the relationship between lexical processing levels in spoken word production. Journal of Memory and Language 38 (3), 313-338.

Griffin, Z.M., Ferreira, V.S., 2006. Properties of spoken language production. Handbook of Psycholinguistics 21-59. 
Hannahs, S., 1995. The phonological word in French. Linguistics 33 (6), 1125-1144.

Harley, T., 1984. A critique of top-down independent levels models of speech production: Evidence from non-plan-internal speech errors. Cognitive Science 8 (3), 191-219.

Inhoff, A.W., Briihl, D., Schwartz, J., 1996. Compound word effects differ in reading, on-line naming, and delayed naming tasks. Memory \& Cognition 24 (4), 466-476.

Jacobs, C., Dell, G., 2014. 'hotdog', not 'hot' 'dog': The phonological planning of compound words. Language, Cognition and Neuroscience 29 (4), 512-523.

Janssen, N., Barber, H.A., 2012. Phrase frequency effects in language production. PLoS ONE 7 (3), e33202.

Janssen, N., Bi, Y., Caramazza, A., 2008. A tale of two frequencies: Determining the speed of lexical access for Mandarin Chinese and English compounds. Language and Cognitive Processes 23 (7-8), 1191-1223.

Jescheniak, J.D., Levelt, W.J., 1994. Word frequency effects in speech production: Retrieval of syntactic information and of phonological form. Journal of Experimental Psychology: Learning, Memory, and Cognition 20 (4), 824.

Jescheniak, J.D., Schriefers, H., Hantsch, A., 2003. Utterance format effects phonological priming in the picture-word task: Implications for models of phonological encoding in speech production. Journal of Experimental Psychology: Human Perception and Performance 29 (2), 441-454.

Jordan, M., 1990. Motor learning and the degrees of freedom problem. Lawrence Erlbaum Associates, Inc.

Lahiri, A., Plank, F., 2010. Phonological phrasing in Germanic: The judgement of history, confirmed through experiment. Transactions of the Philological Society 108 (3), 370-398.

Lange, V.M., Laganaro, M., 2014. Inter-subject variability modulates phonological advance planning in the production of adjective-noun phrases. Frontiers in Psychology 5,43 .

Lange, V.M., Perret, C., Laganaro, M., 2015. Comparison of single-word and adjective-noun phrase production using event-related brain potentials. Cortex 67, 15-29.

Levelt, W., 1989. Speaking. MIT Press.

Levelt, W., 1992. Accessing words in speech production: Stages, processes and representations. Cognition 42 (1), 1-22.

Levelt, W., 2001. Spoken word production: A theory of lexical access. Proceedings of the National Academy of Sciences 98 (23), 13464-13471.

Levelt, W.J., Roelofs, A., Meyer, A.S., 1999. A theory of lexical access in speech production. Behavioral and Brain Sciences 22, 1-75.

Liberman, M., Prince, A., 1977. On stress and linguistic rhythm. Linguistic Inquiry 8 (2), 249-336.

MacKay, D. (1987). Constraints on theories of sequencing and timing in language perception and production. In Language perception and production: Relationships between listening, speaking, reading and writing, Vol. 3, Academic Press London, page 407.

Mahon, B., Costa, A., Peterson, R., Vargas, K., Caramazza, A., 2007. Lexical selection is not by competition: a reinterpretation of semantic interference and facilitation effects in the picture-word interference paradigm. Journal of Experimental Psychology: Learning, Memory, and Cognition 33 (3), 503.

Meyer, A., 1990. The time course of phonological encoding in language production: The encoding of successive syllables of a word. Journal of Memory and Language 29 (5), 524-545.

Meyer, A., 1991. The time course of phonological encoding in language production: Phonological encoding inside a syllable. Journal of Memory and Language 30 (1), 69-89.

Meyer, A., 1996. Lexical access in phrase and sentence production: Results from picture-word interference experiments. Journal of Memory and Language 35 , 477-496.

Meyer, A., Schriefers, H., 1991. Phonological facilitation in picture-word interference experiments: Effects of stimulus onset asynchrony and types of interfering stimuli.
Journal of Experimental Psychology: Learning, Memory, and Cognition 17 (6) 1146.

Morgan, J., Wheeldon, L., 2003. Syllable monitoring in internally and externally generated English words. Journal of Psycholinguistic Research 32 (3), 269-296.

Nespor, M., Vogel, I., 1986. Prosodic phonology Vol. 28, Foris, Dordrecht.

Oldfield, R., Wingfield, A., 1965. Response latencies in naming objects. Quarterly Journal of Experimental Psychology 17 (4), 273-281.

Payne, T., 2006. Exploring language structure: A student's guide. Cambridge University Press.

Peperkamp, S., 1997. Prosodic words Vol. 34, Holland Academic Graphics, The Hague.

Reetz, H. (2010). voicekeyhilary.pl. [Perl Computer program].

Roelofs, A., 1992. A spreading-activation theory of lemma retrieval in speaking. Cognition 107-142.

Roelofs, A., 1993. Testing a non-decompositional theory of lemma retrieval in speaking: Retrieval of verbs. Cognition 47 (1), 59-87.

Roelofs, A., 1997. The WEAVER model of word-form encoding in speech production. Cognition 64 (3), 249-284.

Roelofs, A., Meyer, A.S., 1998. Metrical structure in planning the production of spoken words. Journal of Experimental Psychology: Learning, Memory, and Cognition 24 (4), 922.

Saran, F., 1907. Deutsche Verslehre Vol. 3, CH Beck'sche verlagsbuchhandlung, O. Beck.

Schiller, N., Costa, A., Colomé, A., 2002. Phonological encoding of single words: In search of the lost syllable. Papers in Laboratory Phonology 7, 35-59.

Schneider, W., Eschman, A., Zuccolotto, A., 2002. E-prime computer software and manual. Psychology Software Tools Inc., Pittsburgh, PA.

Schriefers, H., 1992. Lexical access in the production of noun phrases. Cognition 45 (1), 33-54.

Schriefers, H., 1993. Syntactic processes in the production of noun phrases. Journal of Experimental Psychology: Learning, Memory, and Cognition 19 (4), 841.

Schriefers, H., \& Teruel, E. (1999). The production of noun phrases: A cross-linguistic comparison of french and german. In Proceedings of the 21st annual conference of the cognitive science society (pp. 637-642).

Selkirk, E., 1980. The role of prosodic categories in English word stress. Linguistic Inquiry 11 (3), 563-605.

Selkirk, E., 1986. On derived domains in sentence phonology. Phonology 3 (01), $371-405$.

Selkirk, E., 1996. The prosodic structure of function words. Signal to Syntax: Bootstrapping from Speech to Grammar in Early Acquisition 187, 214.

Sternberg, S., Monsell, S., Knoll, R., Wright, C., 1978. The latency and duration of rapid movement sequences: Comparisons of speech and typewriting. In: Information processing in motor control and learning. Academic Press, pp. 117-152.

Sweet, H., 1886. Elementarbuch des gesprochenen Englisch (Grammatik. Clarendon Press, Texte und Glossar).

Vigário, M., 2010. Prosodic structure between the prosodic word and the phonological phrase: Recursive nodes or an independent domain?. The Linguistic Review 27 (4).

Wheeldon, L., Lahiri, A., 1997. Prosodic units in speech production. Journal of Memory and Language 37 (3), 356-381.

Wheeldon, L., Lahiri, A., 2002. The minimal unit of phonological encoding: Prosodic or lexical word. Cognition 85 (2), B31-B41.

Wheeldon, L.R., Levelt, W.J., 1995. Monitoring the time course of phonological encoding. Journal of Memory and Language 34 (3), 311-334.

Wheeldon, L., Morgan, J., 2002. Phoneme monitoring in internal and external speech. Language and Cognitive Processes 17 (5), 503-535.

Zwicky, A.M., Pullum, G.K., 1983. Cliticization vs. inflection: English n't. Language 502-513. 